\title{
Ocorrências de Incêndios Combatidos e Registrados pela Equipe da Reserva Biológica Guaribas
}

\author{
Janderson James Barbosa ${ }^{1} \&$ Afonso Henrique Leal ${ }^{2}$
}

Recebido em 20/11/2020 - Aceito em 11/05/2021

${ }^{1}$ Universidade Federal da Paraíba - UFPB, Campus I, Centro de Ciências Exatas e da Natureza - CCEN, Departamento de Sistemática e Ecologia
- DSE, Brasil. <janderson.james.b@gmail.com>
${ }^{2}$ Instituto Chico Mendes de Conservação da Biodiversidade - ICMBio, Núcleo de Gestão Integrada ICMBio Mamanguape, Rodovia PB 071,
Km 01, Mamanguape, Paraîba, Brasil, CEP: 58.280-000, Brasil. < <afonso.leal@icmbio.gov.br>

RESUMO - A Reserva Biológica (REBIO) Guaribas é uma unidade de conservação (UC) de proteção integral gerida pelo Instituto Chico Mendes de Conservação da Biodiversidade (ICMBio) e tem como objetivo a conservação integral da biota e dos demais atributos naturais. Situa-se no litoral norte da Paraíba, possui mais de 4.000ha divididos em três áreas, denominadas SEMA 1, 2 e 3, sendo a SEMA 2 o maior fragmento de Mata Atlântica entre os estados da Paraíba e Rio Grande do Norte. A unidade de conservação encontra-se em uma área de forte cultivo de cana-de-açúcar, o que eleva o risco de incêndios na vegetação nativa devido à prática da queima pré-colheita, principalmente na estação seca, que ocorre de setembro a março do ano seguinte. O estudo compila informações contidas nos Registros de Ocorrência de Incêndios (ROI) entre os anos de 2007 a 2018 e apresenta o perfil quantitativo dessas ocorrências, identificando a distribuição geográfica dos incêndios, os tipos de vegetação atingidos, as causas do fogo, e sugere propostas para prevenir e combater esses eventos. No período de estudo, foram produzidos $290 \mathrm{ROI}$, correspondendo a 1.251,70ha em área queimada, dos quais 101,93 ha foram dentro da UC. Dos incêndios registrados, 93,4\% aconteceram fora da UC, e desses, 21,0\% ocorreram além da zona de amortecimento. Novembro mostrou-se o mês mais propício ao fogo, com 87 registros, e 2012 foi o ano com a maior área da UC afetada, 27,62ha queimados. Os tipos de vegetação mais atingidos foram, capoeira (aberta e fechada) e mata madura. Além disso, as causas, com poucas exceções, foram antrópicas, das quais práticas agropecuárias e vandalismo figuraram como as mais comuns na região. As áreas menores (1 e 3) apresentaram proporcionalmente maior quantidade de incêndios imediatamente próximos ao entorno, tendo sido observada uma concentração superior de incêndios logo ao norte da SEMA 1. Este é um primeiro esforço para obter um perfil dos incêndios na vegetação natural da REBIO Guaribas $e$ região, embasando o planejamento de atividades para a sua prevenção e combate, bem como para a capacitação de brigadistas.

Palavras-chave: Área protegida; incêndios florestais; registro de ocorrência de incêndio; impactos antrópicos; Floresta Atlântica.

\section{Fire Occurrences Fought and Recorded by Guaribas Biological Reserve Team}

ABSTRACT - The Guaribas Biological Reserve is a no take protected area managed by Instituto Chico Mendes de Conservação da Biodiversidade (ICMBio) and aims at the full conservation of the biota and other natural attributes. Located on the north coast of Paraíba, its area exceeds 4.000ha divided into three areas, called SEMA 1, 2 and 3, which of them SEMA 2 is the largest Atlantic Forest fragment among the Brazilian states of Paraiba and Rio Grande do Norte. The protected area is located in a region of strong sugarcane cultivation for sugar and alcohol production, which increases the risk of fire in native vegetation due to the practice of pre-harvest burning, especially in the dry season, occurring from september to march of the following year. The study compiles information contained in the Fire Occurrence Records (ROI, acronym in Portuguese) between 2007 and 2018 and recognizes the quantitative profile of these occurrences, identifying the geographical distribution 
of the fires, the affected vegetation types, the causes of fire, and proposes measures to prevent and combat these events. In the study period, the reserve's personnel produced $290 \mathrm{ROI}$, corresponding to 1.251.70ha of recorded burned area, from which 101.93ha are located inside the protected area. From the total of fires fought, $93.4 \%$ occurred outside the protected area, $21.0 \%$ beyond the buffer zone. November appeared as the most fire-prone month, with 87 records, 2012 was the year with the greater amount of the protected area affected, with 27.62ha burned. The most affected vegetation types were, respectively, capoeira (open and closed) and mature forest. In addition, the causes, with few exceptions, were anthropic, from which agricultural practices and vandalism were the most common in the region. The smaller areas (1 and 3 ) presented proportionally larger number of fires immediately around, and there was a superiorconcentration of fires just north of SEMA 1 . This is a first effort to obtain a profile of the fires in the natural vegetation in Guaribas Biological Reserve and region, providing bases for planning of activities for their prevention and combat, as well as to the training of firefighters.

Keywords: Protected area; wildfires; fire record occurrence; anthropic impacts; Atlantic Forest.

\section{Incendios Combatidos y Registrados por el Equipo de la Reserva Biológica Guaribas}

RESUMEN - La Reserva Biológica (REBIO) Guaribas es una unidad de conservación de protección integral administrada por el Instituto Chico Mendes de Conservação da Biodiversidade (ICMBio) y tiene como objetivo preservar completamente la biota y otros atributos naturales. Ubicada en la costa norte de Paraíba, tiene más de 4.000ha divididas en tres áreas, llamadas SEMA 1, 2 y 3 , siendo SEMA 2 el fragmento más grande del Bosque Atlántico entre los estados brasileños de Paraíba y Rio Grande do Norte. La unidad de conservación (UC) está ubicada en un área de fuerte cultivo de caña para la producción de azúcar y alcohol, fator que aumenta el riesgo de incendio en la vegetación nativa debido a la práctica de la quema previa a la cosecha, principalmente en la estación seca, que ocurren de septiembre a marzo del año siguiente. El estudio recopila información contenida en los Registros de Ocurrencia de Incendios (ROI) entre los años 2007 a 2018 y reconoce el perfil cuantitativo de estas ocurrencias, identifica la distribución geográfica de incendios, los tipos de vegetación afectados, las causas del incendio, y presenta propuestas para prevenir y combatir estos eventos. En el período de estudio, se produjeron 290 ROI, correspondiendo a 1.251,70ha de área quemada, con 101,93ha dentro de la UC. De los incendios combatidos, 93,4\% ocurrieron fuera de la UC, con $21,0 \%$ más allá de la zona de amortiguamiento. Noviembre resultó el mes más propenso a incendios, con 87 registros, y 2012 fue el año con el área más grande de la UC afectada, 27.62ha de área quemada. Los tipos de vegetación más afectados fueron capoeira (abierta y cerrada) y bosque maduro, respectivamente. Además, las causas, con pocas excepciones, son antrópicas, las prácticas agropecuarias y el vandalismo figuran como las más comunes en la región. Las áreas más pequeñas (1 y 3) mostraron una cantidad proporcionalmente mayor de incendios inmediatamente alrededor del área. Finalmente, se observó una concentración superior de incendios justo al norte de la SEMA 1. Se trata de un primer esfuerzo por obtener un perfil de incendios en la vegetación natural de REBIO Guaribas y región, generando bases para la planificación de actividades para su prevención y combate, así como para la capacitación de los brigadistas.

Palabras clave: Área protegida; incendios forestales; registro de ocurrencia de incendios; impactos antrópicos; Bosque Atlántico.

\section{Introdução}

Recentemente, tem-se debatido a aplicação do manejo do fogo, incluindo seu uso, em favor da conservação da biodiversidade nas áreas protegidas, como as unidades de conservação (UCs). No entanto, a prevenção e o combate de sua forma descontrolada sobre a vegetação natural ainda são uma constante preocupação da gestão ambiental (Ribeiro et al., 2011; Sampaio et al., 2016).

As causas dos incêndios florestais são comumente agrupadas na literatura internacional em categorias tais como raios, incendiários, queimas para a limpeza, operações florestais, fumantes, fogos de recreação e estradas de ferro 
(Batista 2000; Santos et al., 2006). As causas mais frequentes desse tipo de incêndio são as de origem antrópica (Batista, 2000; Koproski et al., 2004; Medeiros \& Fiedler, 2004), sendo os incendiários comumente registrados como a principal causa em unidades de conservação (Koproski et al., 2004; Medeiros \& Fiedler, 2004; Fiedler et al., 2006; Santos et al., 2006).

Na Mata Atlântica, também é registrada a prática de atear fogo em áreas abandonadas para manter a possibilidade de uso futuro, uma vez que a Lei da Mata Atlântica (Lei Federal n 11.428/2006) restringe severamente a supressão da floresta secundária a partir do estágio médio de sucessão (Aximoff, 2011). O bioma, que se estendia originalmente por quase toda costa brasileira, encontra-se seriamente fragmentado, possuindo apenas cerca de $8,5 \%$ de sua cobertura original (Leitão-Filho, 1994; Myers et al., 2000; Melo \& Vieira, 2017) e é considerado um hotspot de biodiversidade por seu alto grau de endemismo e de ameaça (MMA, 2019). Somando-se a isso, os incêndios florestais podem ser considerados um dos principais fatores que impedem a regeneração natural da Mata Atlântica, sendo seu controle essencial para a restauração da floresta no bioma (dos Santos et al., 2019).

Na Reserva Biológica Guaribas (REBIO Guaribas) há o registro de 56 espécies de animais e seis de plantas constantes em alguma lista oficial de espécies ameaçadas (Luna, 2015) e, pelo menos, parte dessas pode ser negativamente impactada pela ação do fogo. No entanto, desconhecemos a gravidade dos efeitos dos incêndios a essas espécies na reserva. De forma análoga, nos ambientes de Campos de Altitude presentes no Parque Nacional do Itatiaia, no Rio de Janeiro, Aximoff (2011) alerta para o risco de as espécies ameaçadas não tolerantes ao fogo e passarem a depender de conservação ex situ para sua sobrevivência.

A REBIO Guaribas está inserida em uma matriz com alto predomínio da monocultura da cana-de-açúcar, na qual emprega-se o fogo para despalhamento antes da colheita (IBAMA, 2003; Silva et al., 2017). Devido a essa prática, somada à negligência quanto às técnicas preventivas, como a construção e manutenção de aceiros, o fogo da cana-de-açúcar frequentemente alastra-se para fragmentos florestais em torno ou pertencentes à unidade de conservação (Silva et al., 2017).

Neste trabalho, identificamos o perfil dos incêndios combatidos e registrados pela equipe da REBIO Guaribas, com o intuito de apresentar informações para orientar melhorias na prevenção e no combate ao fogo. Especificamente, registramos: as prováveis causas; a distribuição temporal ao logo ano e entre os anos; o tamanho da área queimada; e a distribuição geográfica na área de estudo.

\section{Material e Métodos}

\section{Área de estudo}

Localizada na região do litoral norte do Estado da Paraíba, a Reserva Biológica (REBIO) Guaribas protege 4.321 ha de florestas e formações savânicas (IBAMA, 2003) na porção da Mata Atlântica ao norte do Rio São Francisco conhecida como Centro de Endemismo de Pernambuco (Pôrto et al., 2006). Ela é formada por três áreas disjuntas denominadas SEMA 1 e SEMA 2, no município de Mamanguape, e SEMA 3, no de Rio Tinto, com 673,64ha, 3.016,09ha e 338,82ha, respectivamente. O clima na região onde a reserva está inserida é quente e úmido, tendo uma estação seca no verão e chuvosa no inverno (IBAMA, 2003).

Foi considerada toda a distribuição geográfica dos incêndios registrados pelos servidores e brigadistas de prevenção e combate aos incêndios florestais da REBIO Guaribas. Isso equivale às áreas que compõem a própria reserva $e$ às áreas onde se presume que impactos a afetem, bem como unidades de conservação federais vizinhas: Área de Proteção Ambiental da (APA) Barra do Rio Mamanguape e Área de Relevante Interesse Ecológico (ARIE) Manguezais da Foz do Rio Mamanguape (Fig. 1). Na época dos registros, havia uma gestão separada para a REBIO Guaribas e outra para a APA e a ARIE do Rio Mamanguape. A partir de 2018, as gestões foram oficialmente unificadas na forma do Núcleo de Gestão Integrada ICMBio Mamanguape, que se encontra em processo de implementação. 


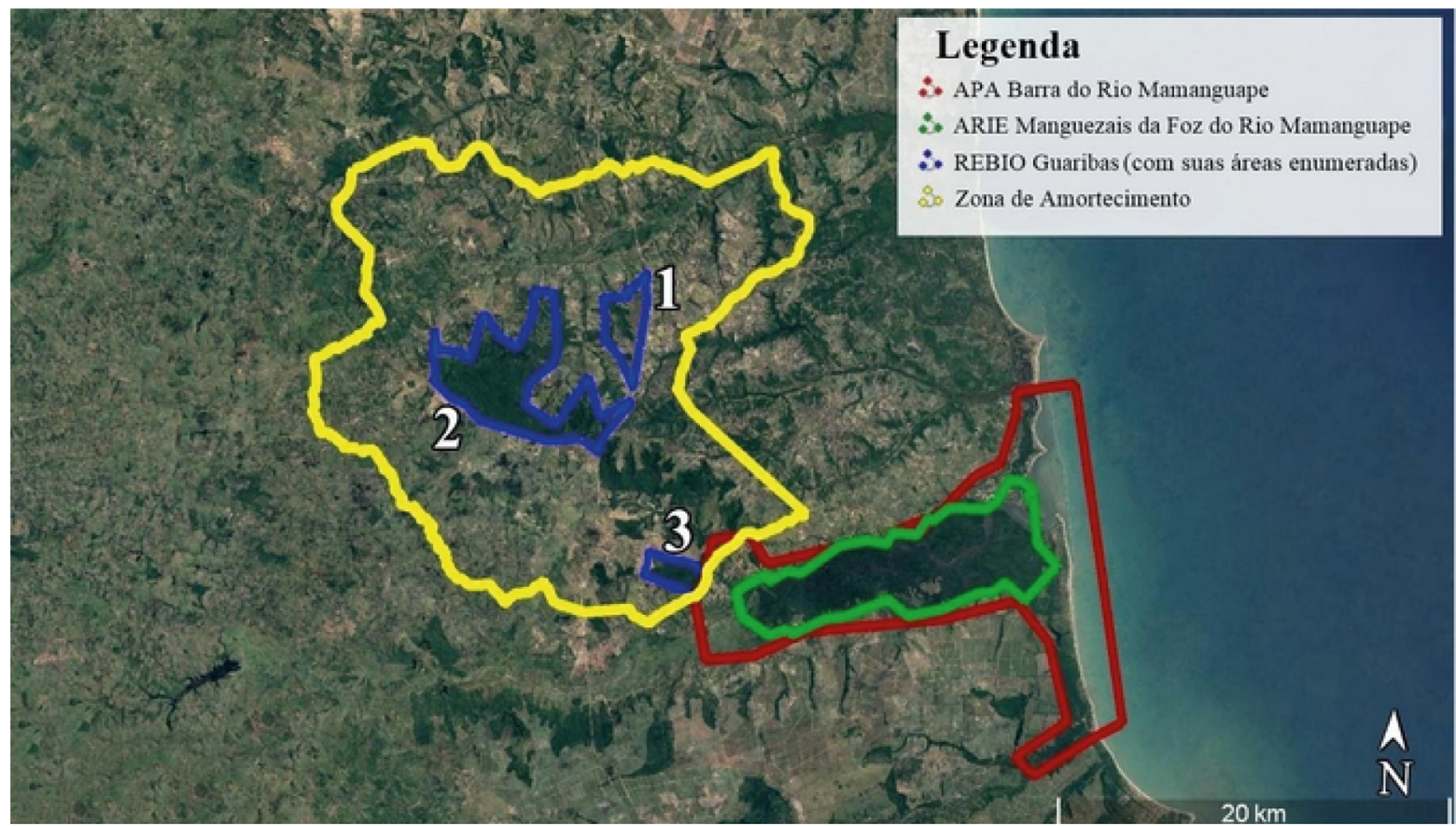

Figura 1 - Imagem de satélite daárea de estudo. APA da Barra do Rio Mamanguape em vermelho, ARIEManguezais da Foz do Rio Mamanguape em verde e REBIO Guaribas em azul (com numerais indicando as SEMAs 1,2 e 3) e sua zona de amortecimento em amarelo.

\section{Coleta e análise de dados}

Para o presente estudo foi utilizado o arquivo documental de Registros de Ocorrência de Incêndio (ROI) da REBIO Guaribas dos anos de 2007 a 2018. O ROI é um documento padronizado, adotado pelas unidades de conservação, que registra dados aplicáveis à melhoria da prevenção, controle e combate aos incêndios. Esses dados referem-se à localização do incêndio, características do terreno, condições meteorológicas, informações do combate, gastos efetuados, origem e causa e danos, tais como a área queimada, animais mortos e tipo de vegetação atingida (Bontempo et al., 2011).

Para obter um perfil tipológico, espacial e temporal dos incêndios, foram compilados os seguintes dados em uma planilha eletrônica: coordenadas geográficas; interior ou entorno da UC; tipo de local (REBIO Guaribas, dentro dos limites da zona de amortecimento [ZA], além dos limites da ZA e outras UCs); ano da ocorrência; mês; causa; tipo de vegetação nativa atingida; tamanho da área queimada; presença animais mortos; e o tempo decorrido entre o início e a extinção do fogo. Os dados foram quantificados e expressos em números absolutos, porcentagens $e$ representados na forma de gráficos.
Quanto aos tipos de vegetação atingidos, deve-se ressaltar que, antes de 2015, o ROI da REBIO Guaribas possuía o tópico referente ao tipo de vegetação atingida de maneira muito ampla $e$ sem opções objetivas, o que causava variabilidade nos preenchimentos quanto às fitofisionomias atingidas. A partir de 2015 o ROI foi modificado $e$ os tipos de vegetação foram regionalizados em mata madura, capoeira aberta, capoeira fechada, tabuleiro, paul-alagadiço (diferentes tipos de vegetação associados a áreas úmidas alagáveis) $e$ área antropizada. Essa nova nomenclatura foi definida em colaboração da gestão da reserva com os brigadistas durante o treinamento do ciclo 2014-2015.

Casos de ROIs específicos com mais de um polígono de incêndio registrados simultaneamente no mesmo lugar foram interpretados como um mesmo incêndio atingindo mais de uma área. Portanto, cada conjunto foi considerado apenas como uma única ocorrência sendo o total da área queimada o somatório dos polígonos de cada ROI. Para a visualização dos pontos do $\mathrm{ROI}$ e verificação de conflitos geográficos, as coordenadas foram inseridas e salvas no Google Earth Pro na versão 7.3.2.5491 64-bit (2018), e, para a montagem do mapa de Kernell, foi utilizado o Quantum GIS na versão 2.18.26 64-bit (QGIS Development Team, 2018). 


\section{Resultados e Discussão}

No período de estudo, foram gerados 290 ROIs. No que tange ao tipo de local (Fig. $2 \mathrm{~A})$, apenas 19 registros $(6,6 \%)$ ocorreram na UC, considerando tanto os localizados completamente no interior da REBIO como também aqueles parte dentro e parte fora da unidade. Dos que ocorreram fora, 199 registros (68,6\%) localizam-se dentro da zona de amortecimento e 61 registros $(21,0 \%)$ além desta, desconsiderando os ocorridos na APA e na ARIE do Rio Mamanguape. Incluindo nesta categoria os ocorridos nas referidas unidades de conservação, esse número passa para 72 registros (24,8\%). Ou seja, 93,4\% (271 registros) dos incêndios combatidos aconteceram fora da REBIO Guaribas.

Esses resultados demonstram o esforço da gestão em combater incêndios fora dos limites da UC, justamente considerando a importância dos fragmentos de vegetação nativa próximos para a conservação da própria biodiversidade na REBIO. Esforço semelhante é observado na coibição de ilícitos ambientais no entorno da reserva, conforme mapa desenvolvido por Camargo (2019). Nas ações citadas, de combate a incêndios e fiscalização ambiental, a zona de amortecimento serve como um importante instrumento de gestão para se reconhecer áreas no entorno onde os servidores do ICMBio estão legitimados a atuar, como forma de prevenir ou mitigar impactos indiretos à unidade de conservação. No caso da REBIO Guaribas, a zona de amortecimento foi instituída por meio de um mapa em seu plano de manejo (IBAMA, 2003), de forma que seu valor legal pode vir a ser questionado, bem como das ações desenvolvidas pelos servidores fora das áreas que compõem a unidade.

Além disso, o registro de combates na APA e ARIE do Rio Mamanguape indica a existência de alguma interação entre a gestão dessas unidades de conservação federais e a REBIO Guaribas. Provavelmente, com a implementação do Núcleo de Gestão Integrada ICMBio Mamanguape, unificando a gestão das três UCs, deverá elevar a quantidade de combates nas unidades vizinhas à REBIO Guaribas e possivelmente demandará melhorias na estrutura da brigada de prevenção $e$ combate a incêndios florestais.

Quantoaotipodevegetaçãonanomenclatura anterior, as mais atingidas foram o tabuleiro e a capoeira, ambos com 50 registros (24,5\% cada), seguidas por floresta densa (46 registros, 22,5\%), mata secundária (35 registros e 17,2\%) e outros tipos menos expressivos (Fig. 2B). Considerando a nomenclatura vigente, a mata madura foi o tipo com mais ocorrências (26 registros, 30,2\%), seguido por capoeira aberta (25 registros, $29,1 \%$ ) e capoeira fechada (19 registros, 22,1\%) (Fig. 2C). Nota-se uma disparidade entre os resultados com as diferentes nomenclaturas, uma vez que, com a nomenclatura anterior (Fig. 2B), os dois tipos predominantes, com quase um quarto das ocorrências cada, são vegetações abertas (tabuleiro e capoeira), enquanto, de acordo com a nomenclatura vigente, dos dois mais registrados, com quase um terço cada, um é vegetação fechada (mata madura) e o outro aberta (capoeira aberta). Isso pode estar relacionado ao preenchimento do ROI pelos brigadistas, ou seja, não necessariamente indica mudanças fitofisionômicas ao longo do tempo.

Entendemos que os dados mais confiáveis sejam os mais recentes, pois, com a reformulação da nomenclatura, adotaram-se nomes que são popularmente usados pela comunidade local $e$ foram eliminados nomes técnicos, bem como outros que não representavam tipos vegetacionais ou que eram ambíguos. Por exemplo, tabuleiro é o nome popular local para a vegetação considerada um encrave de Cerrado na Mata Atlântica nordestina (IBAMA, 2003), não devendo haver as duas opções para serem assinaladas.

Além disso, a Área de Preservação Permanente (APP) refere-se a um tipo de proteção legal à vegetação nativa, na qual pode haver diferentes tipos vegetacionais. Assim como foi percebida a manutenção acidental de dois tipos (área antropizada e vegetação em regeneração), também se verificou a necessidade manter o tipo mangue, que havia sido retirado. Apesar de não haver manguezais na REBIO Guaribas e entorno imediato, esta é uma das fitofisionomias mais importantes da APA e da ARIE do Rio Mamanguape.

O trabalho de Aximoff \& Rodrigues (2011) aponta pastagem e capoeira somando $49,0 \%$ das vegetações atingidas, seguidos por campos de altitude $(28,9 \%)$, floresta altomontana $(10,7 \%)$ e floresta $(10,1 \%)$. Considerando a nomenclatura vigente do adotada no ROI da REBIO Guaribas, encontra-se um resultado semelhante com capoeira aberta $(29,1 \%)$, capoeira fechada $(22,1 \%)$ e mata madura $(30,2 \%)$ sendo as fitofisionomias mais atingidas (Fig. 2C). As causas mais comuns dos incêndios foram: desconhecida (111 registros, 
$38,3 \%$ ), queima de cana-de-açúcar (52 registros, $17,9 \%$ ), vandalismo (45 registros, $15,5 \%$ ) e limpeza de área para cultivo (30 registros, 10,3\%) (Fig. 2D). A maior parte dos incêndios com causa desconhecida encontra-se nos anos anteriores a 2010, o que indica uma crescente preocupação no preenchimento adequado dos $\mathrm{ROIs}$ por parte dos servidores e brigadistas.

Esses resultados condizem com o registro da literatura de que as causas antrópicas são as mais frequentes (Batista, 2000; Koproski et al., 2004; Medeiros \& Fiedler, 2004). Embora os incendiários não foram registrados como a principal causa, como registrado em outras unidades de conservação (Koproski et al., 2004; Medeiros \& Fiedler, 2004; Fiedler et al., 2006; Santos et al., 2006), o vandalismo também foi uma causa importante neste estudo. Uma possível explicação para essa conjuntura seriam retaliações de infratores à ação fiscalizatória ambiental ou à burocracia para realização de queimadas controladas (Mistry \& Bizerril, 2011). A gestão da UC observa que as medidas preventivas a incêndios referentes à queima controlada, mesmo obrigatórias segundo a legislação (p. ex: Decreto $n^{\circ}$ 2.661/1998), costumam ser parcialmente ou totalmente descumpridas pelos agricultores, provavelmente como forma de manter maiores áreas de cultivo, visto que áreas com aceiros perdem espaços que podem ser utilizados no plantio.

Diferentemente de nosso trabalho, Magalhães (2011) investigando as causas de incêndios no Parque Nacional Serra da Canastra, constatou que a maioria dos incêndios acontece de forma natural $(40,18 \%)$. As ações antrópicas figuram com $32,42 \%$ por vandalismo (incendiários) e $10,5 \%$ por limpeza de pastagem, tendo apenas $4,53 \%$ dos registros com causa desconhecida.

Na REBIO Guaribas os incêndios ocorrem, principalmente, devido à queima de cana-deaçúcar $e$ ao vandalismo, já as causas naturais figuram como eventos raros. Isso sugere que, assim como a fitofisionomia, as causas de incêndios para as unidades de conservação são regionalizadas, pois variam as condições de vegetação e clima, assim como as formas de uso e ocupação do solo.
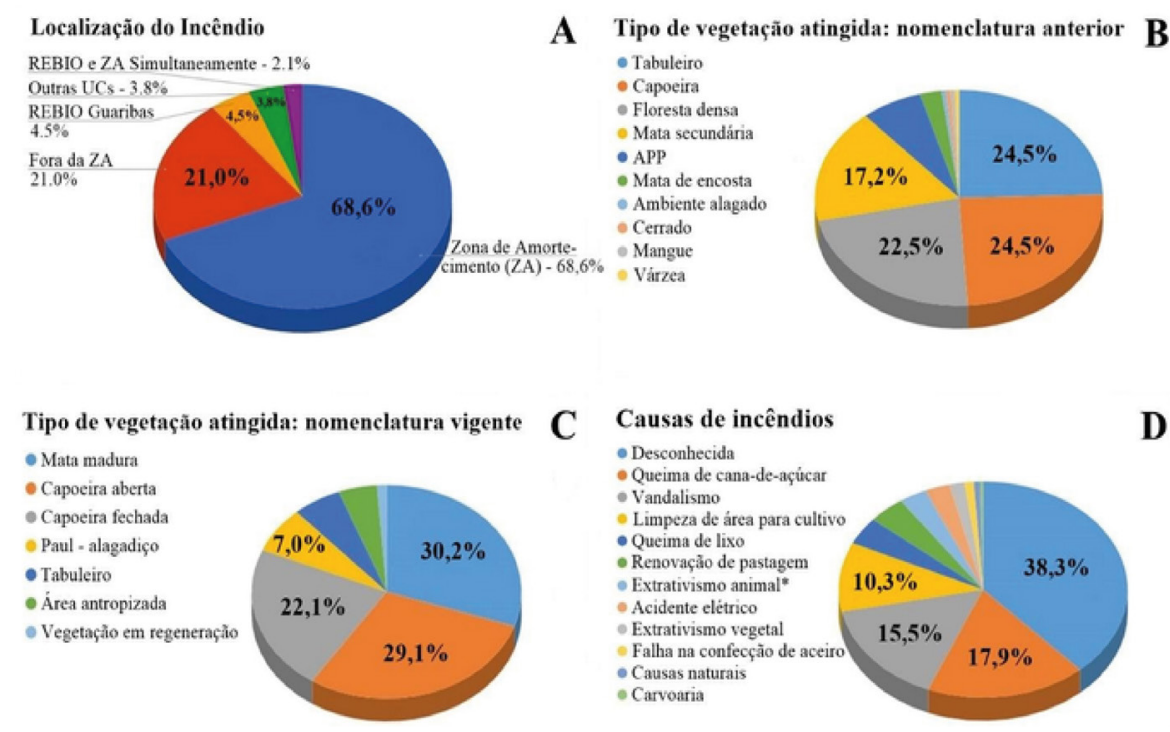

D

Figura 2 - Proporção de ocorrências de incêdios na vegetação nativa registrados pela gestão da REBIO Guaribas por: localidade $(\mathrm{A})$; vegetação, segundo a nomenclatura anterior $(\mathrm{B})$ e nomenclatura vigente $(\mathrm{C})$; $e$ causa (D).

Quanto à sazonalidade, verifica-se que novembro é o mês de maior registro de incêndios na região (87), seguido por dezembro (65) e outubro (56), com novembro apresentando uma área queimada representativamente extensa, de 445,39ha nos anos analisados (Fig. 3A).
Magalhães (2011), Brandão (2012) e Nunes (2015) investigaram, respectivamente, os meses com mais eventos de incêndio no Parque Nacional da Serra da Canastra, no Parque Estadual da Pedra Branca e no Parque Nacional do Itatiaia e demonstraram que o período mais alarmante 
ocorre entre junho e outubro, sendo julho o mês mais crítico. De forma completamente distinta, o período mais preocupante para a REBIO Guaribas estende-se de setembro a março, sendo novembro o mês mais crítico. Esta divergência se dá tanto pelas diferenças na época em que ocorre a estação seca em cada região, quanto pelo período da queima de cana, que, no litoral norte paraibano, acontece de setembro a março (Silva et al., 2017). Cabe observar que os meses com mais incidência de incêndios, além de estarem na estação seca, também estão no período do contrato da brigada de incêndios. A ação dos brigadistas favorece a geração de registros, tendo em vista um grande aumento na quantidade de pessoas envolvidas na atividade. Da mesma maneira, entre os meses de abril e setembro, quando os registros foram nulos ou muito baixos, a incidência real pode ser maior pela falta de equipe direcionada aos incêndios. Como o período da queima de cana-de-açúcar inicia-se em setembro e, com o início da brigada em outubro, é provável que a incidência de setembro esteja subestimada.

Nos anos amostrados, foi contabilizada uma queima total de 1.251,70ha, sendo apenas 101,93ha no interior da REBIO Guaribas. Em todo período, 2008 apresentou o maior número de incêndios (47 registros), seguido por 2016 (31 registros), no entanto, 2012 foi o ano de maior área queimada na UC, 27,62ha (Fig. 3B). $\mathrm{Na}$ série temporal examinada, percebe-se uma oscilação nos valores registrados, o que é ainda mais claro considerando a área queimada, exceto pelo período entre 2013 e 2016, que apresenta um aumento nos valores registrados. A explicação para isso pode envolver diversos fatores atuando de forma isolada ou integrada, dentre eles variações climáticas, mudanças nas práticas de queima controlada e oscilações no consumo de biomassa pelos próprios incêndios.

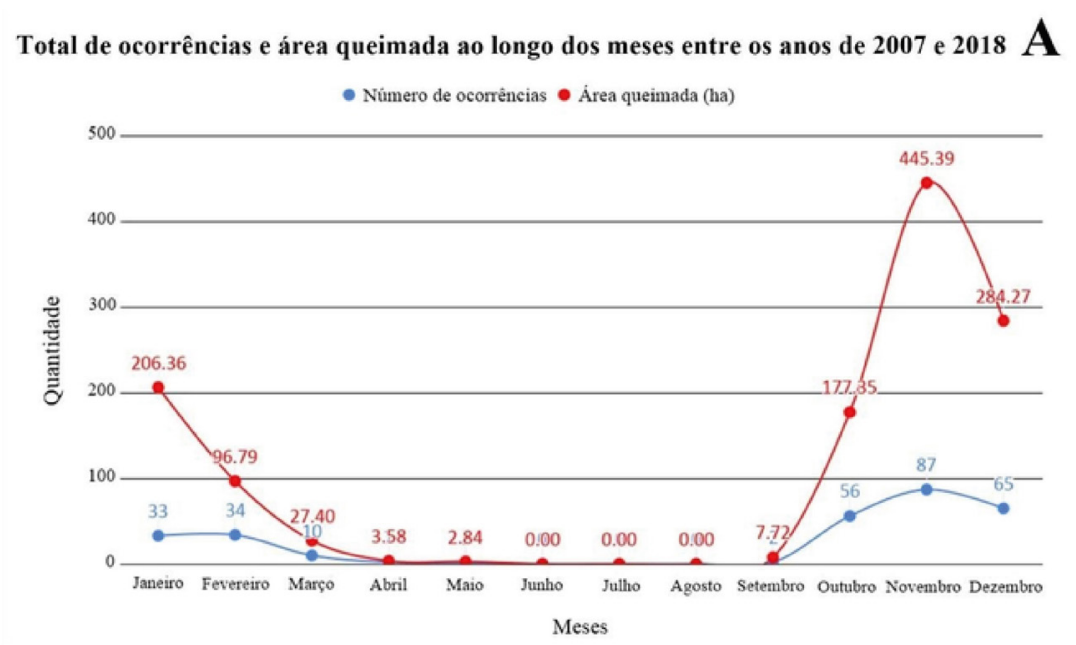

Total de ocorrências e área queimada entre os anos de 2007 e $2018 \quad$ B

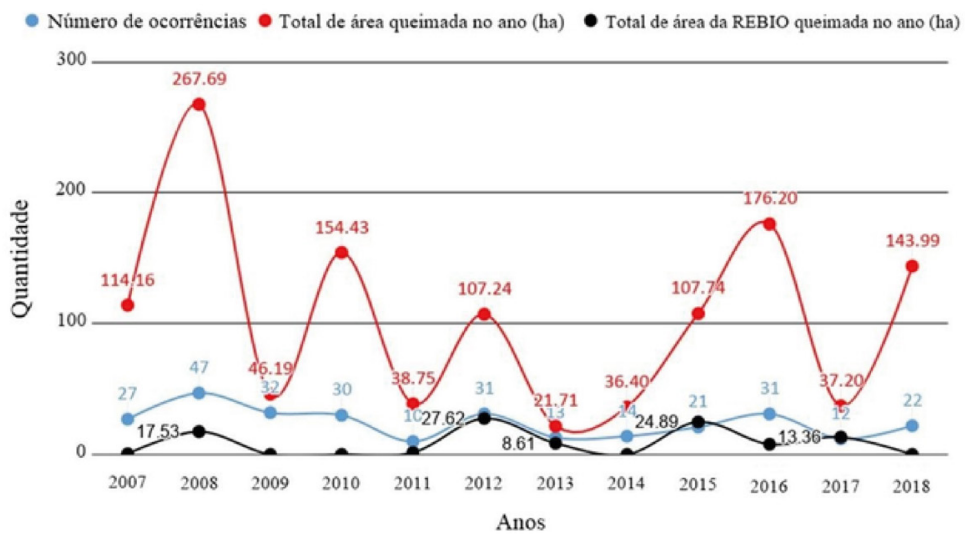

Figura 3 - Distribuição temporal da totalidade dos incêndios por número de ocorrências e área queimada: ao longo dos meses do ano (A) e ao longo dos anos no período de estudo (B). 
Em relação à distribuição geográfica dos incêndios, sua maior concentração foi no limite imediato do setor SEMA $1 \mathrm{com}$ as propriedades rurais vizinhas ao norte, havendo também uma área de alta incidência entre as SEMAs 1 e 2 (Fig. 4). A SEMA 1 é uma área com predominância da vegetação de tabuleiro (IBAMA, 2003), que é, ao mesmo tempo, mais suscetível e mais resiliente ao fogo, onde se localiza a zona intangivel da UC, ou seja, a de maior proteção (IBAMA, 2003).
Leal et al. (2020) atribuem valor para a conservação aos tabuleiros por eles conterem uma biodiversidade distinta da Mata Atlântica circundante e por sugerirem que parte de sua biota está passando por um processo de diferenciação evolutiva daquela típica do Cerrado. Além de reforçar a prevenção de incêndios na área, outra medida a ser tomada seria a incorporação das terras entre as SEMAs 1 e 2 à REBIO Guaribas, conforme recomentado em seu plano de manejo (IBAMA, 2003).

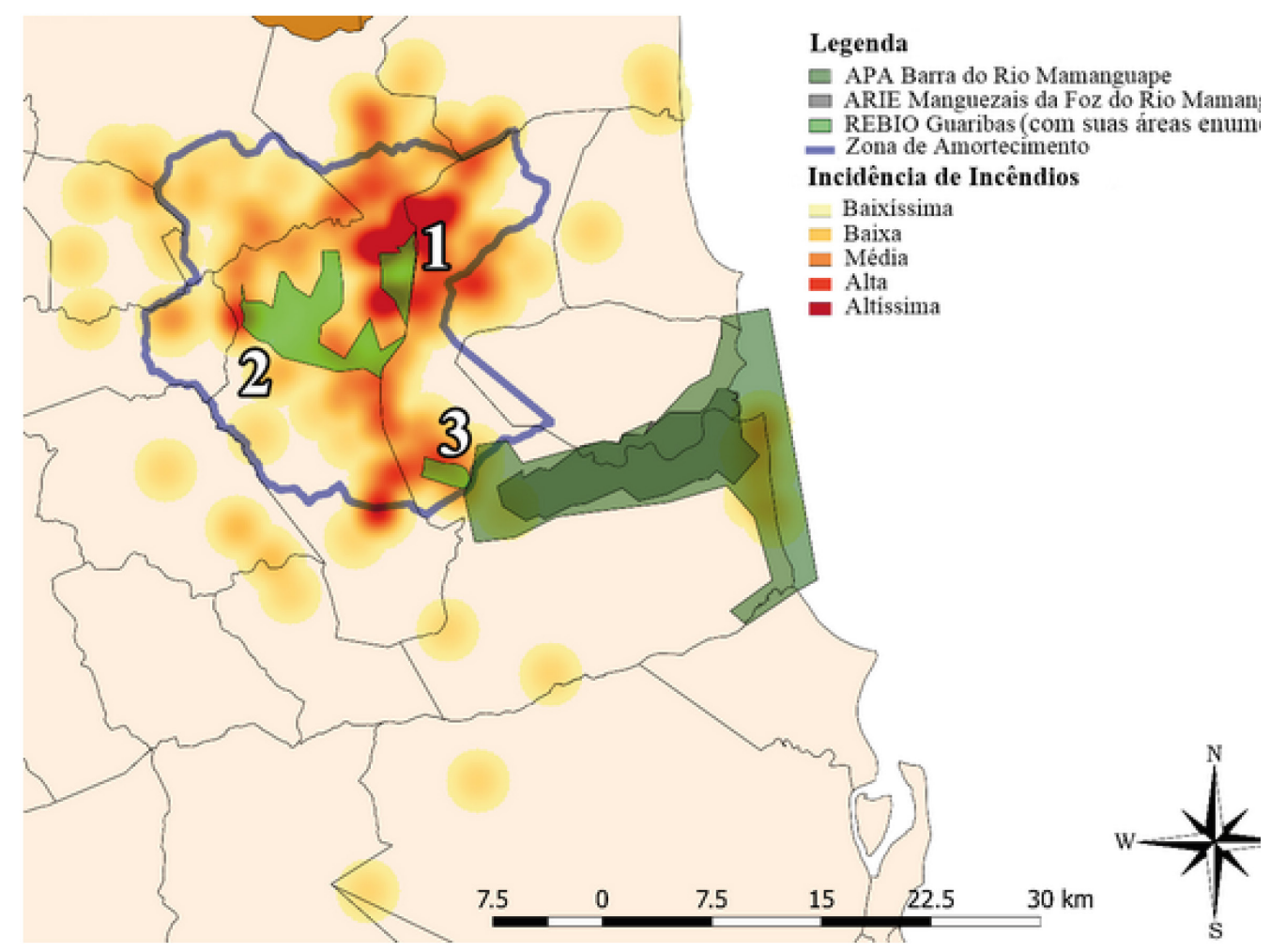

Figura 4 - Mapa de Kernell, cuja intensidade da cor representa uma maior incidência de incêndios registrados pela REBIO Guaribas.

\section{Conclusões}

O presente estudo é um primeiro esforço para se estabelecer um perfil dos incêndios na vegetação natural da REBIO Guaribas e região, como forma de orientar melhorias na gestão das atividades desenvolvidas para a prevenção $e$ combate ao fogo, bem como um incentivo ao debate do tema em relação às UCs em geral. Reforçamos a importância da existência de uma zona de amortecimento, que cumpre o papel de legitimar as atividades da equipe do ICMBio no entorno da UC, dada a importância de se proteger os fragmentos externos de vegetação natural para conservar a biodiversidade interna da REBIO Guaribas.
Observamos que o tipo de vegetação atingida, as causas e a época de ocorrência estão relacionadas às atividades humanas, visto que pelo menos $61,0 \%$ dos ROIs analisados apontam para causas antrópicas, podendo haver mais dentre as causas desconhecidas. Também é possível concluir que a capacitação dos brigadistas pode melhorar o registro dos incêndios e o consequente planejamento das atividades para sua prevenção e combate. No entanto, para que a referida brigada da REBIO Guaribas seja efetivamente convertida em brigada do Núcleo de Gestão Integrada ICMBio Mamanguape, deverá haver também um investimento em equipe e estruturas, para melhor atender as áreas de maior interesse da APA e ARIE do Rio Mamanguape. 


\section{Agradecimentos}

Esta pesquisa foi autorizada pelo ICMBio por meio da autorização SISBIO n 65364-1. Uma bolsa do Conselho Nacional de Desenvolvimento Científico e Tecnológico sob n 139010/2018-1 foi concedida a JJB durante seu estágio de iniciação científica. A versão final deste artigo beneficiouse significativamente pelos comentários e críticas de dois revisores anônimos e pela condução do processo por Elizabeth Albuquerque (ICMBio). Agradecemos à contribuição do gerente do fogo Ivaldo Marques da Silva, que coordena a brigada de Prevenção e Combate a Incêndios do Núcleo de Gestão Integrada ICMBio Mamanguape, pelo acesso ao arquivo de ROIs da REBIO Guaribas e esclarecimentos prestados.

\section{Referências}

Aximoff I. O que perdemos com a passagem do fogo pelos Campos de Altitude do Estado do Rio de Janeiro? Biodiversidade Brasileira, 2: 180-200, 2011.

Aximoff I, Rodrigues RC. Histórico dos incêndios florestais no Parque Nacional do Itatiaia. Ciência Florestal, 21(1): 83-92, 2011.

Batista AC. Mapas de risco: uma alternativa para o planejamento de controle de incêndios florestais. Floresta, 30(1/2): 45-54, 2000.

Bontempo GC, Lima GS, Ribeiro GA, Doula SM, Silva E, Jacovane LAG. Registro de Ocorrência de Incêndio (ROI): evolução, desafios e recomendações. Biodiversidade Brasileira, 1(2): 247-263, 2011.

Brandão CB, Miranda RAC. Relações entre elementos climáticos e geográficos nas ocorrências de incêndio florestal no Parque Estadual da Pedra Branca - RJ. Revista Brasileira de Climatologia, 10(1): 171-184, 2012.

Camargo MA. 2019. Ilícitos ambientais que afetam a Reserva Biológica Guaribas e medidas de controle. Relatório Final (PIBIC/ICMBio). 27p.

dos Santos JFC, Gleriani JM, Velloso SGS, Souza GSA, Amaral CH, Torres FTP, Medeiros NG, Reis M. Wildfires as a major challenge for natural regeneration in Atlantic Forest. Science of the Total Environment. 650: 809821, 2019.

Fiedler NC, Merlo DA, Medeiros MB. Ocorrência de incêndios florestais no Parque Nacional da Chapada dos Veadeiros, Goiás. Ciência Florestal. 16(2): 153161, 2006.

IBAMA (Instituto Brasileiro do Meio Ambiente e dos Recursos Naturais Renováveis). 2003. Plano de Manejo da Reserva Biológica Guaribas. 520p.
Koproski LP, Batista AC, Soares RV. Ocorrências de Incêndios Florestais no Parque Nacional de Ilha Grande - Brasil. Floresta. 34(2): 193-197, 2004.

Leal AH, Creão-Duarte AJ, \& Mejdalani G. Phylogenetic analysis of the South American sharpshooter genus Scopogonalia Young, 1977 (Insecta: Hemiptera: Cicadellidae), with implications for conservation. Zootaxa. 4885 (4): 487-508, 2020.

Leitão-Filho HF. 1996. Diversity of Arboreal Species in Atlantic Rain Forest, p. 91-96. In: Anais da Academia Brasileira de Ciências. 66: 90-96, 1994. 281p.

Luna MMA. 2015. Vertebrados Terrestres e Plantas Como Alvos de Conservação e Subsídios à Gestão da REBIO Guaribas. Relatório Final (de estágio PIBIC/ ICMBio). ICMBio. 88p.

Magalhães SR, Lima GS, Ribeiro GA. Avaliação dos Incêndios Florestais Ocorridos no Parque Nacional da Serra da Canastra. Cerne. 18(1): 135-141, 2012.

Medeiros MB, Fiedler NC. Incêndios Florestais no Parque Nacional da Serra da Canastra: Desafios Para a Conservação da Biodiversidade. Ciência Florestal. 14(2): 157-168, 2004.

Melo JIM, Vieira DD. Flora da Reserva Biológica Guaribas, PB, Brasil: Boraginaceae. Hoehnea. 44(3): 407-414, 2017.

Mistry J, Bizerril M. Por que é importante entender as inter-relações entre pessoas, fogo e áreas protegidas? Biodiversidade Brasileira. 2: 40-49, 2011.

MMA (Ministério do Meio Ambiente). Mata Atlântica. Ministério do Meio Ambiente. <http://www.mma. gov.br/biomas/mata-atl\%C3\%A2ntica>. Acesso em: 02/02/2019.

Myers N, Mittermeier RA, Mittermeier GM, Fonseca GAB, Kent J. 2000. Biodiversity Hotspots for Conservation Priority. Nature. 403: 853-858, 2000.

Nunes MTO, Sousa GM, Tomzhinski GW, Oliveira-Júnior JF, Fernandes MC. 2015. Variáveis Condicionantes na Susceptibilidade de Incêndios Florestais no Parque Nacional do Itatiaia, p. 54-62. In: Anuário do Instituto de Geociências - UFRJ. 729p.

Pôrto KC, Almeida-Cortez JS, Tabarelli M. 2006. Diversidade Biológica e Conservação da Floresta Atlântica ao Norte do Rio São Francisco. 14ed. Biodiversidade. 363p.

Ribeiro KT, França H, Miranda HS, Berlinck CN. Editorial: Manejo do fogo em Áreas Protegidas. Biodiversidade Brasileira. 1(2): 1-3, 2011.

Sampaio AB, Berlinck CN, Miranda H, Schmidt IB, Ribeiro KT. Editorial: Manejo do Fogo em Áreas Protegidas. Biodiversidade Brasileira. 6(2): 1-3, 2016. 
Santos JF, Soares RV, Batista AC. Perfil dos Incêndios Florestais no Brasil em Áreas Protegidas no Período de 1998 a 2002. Floresta. 36(1): 93-100, 2006.

Silva IM, Freitas, GL, Leal, AH. 2017. Plano de Manejo Integrado do Fogo [da Reserva Biológica Guaribas]. Processo SEI/ICMBio no 02070.009424/2017-98, 24p.

Biodiversidade Brasileira - BioBrasil.

Edição Temática: PIBIC

n. 1,2022

http://www.icmbio.gov.br/revistaeletronica/index.php/BioBR

Biodiversidade Brasileira é uma publicação eletrônica científica do Instituto Chico Mendes de Conservação da Biodiversidade (ICMBio) que tem como objetivo fomentar a discussão e a disseminação de experiências em conservação e manejo, com foco em unidades de conservação e espécies ameaçadas.

ISSN: 2236-2886 